\title{
A supervisão psicanalítica: revisão e uma proposta de sistematização
}

\author{
Jacó Zaslavsky* \\ Maria Lúcia Tiellet Nunes** \\ Cláudio Laks Eizirik***
}

\section{INTRODUÇÃO}

A formação psicanalítica está alicerçada sobre três pilares básicos: a análise didática, os seminários teóricos e a supervisão clínica de análises.

A presente revisão tem como finalidade apresentar uma proposta de sistematização dos aspectos da supervisão psicanalítica, visando a contribuir para uma área ainda em desenvolvimento e que conta com crescentes contribuições realizadas em nosso meio e fora dele.

O modelo de supervisão psicanalítica, como um todo ou parte dele, é utilizado em diversas áreas do ensino da medicina, da psiquiatria e da psicologia, principalmente na psi-

\footnotetext{
* Psiquiatra pela UFRGS. Psicanalista pela SPPA (IPA). Professor Colaborador e Supervisor do Departamento de Psiquiatria e Medicina Legal da FAMED/UFRGS-CELG. Mestrando do Programa de PósGraduação em Ciências Médicas: Psiquiatria da UFRGS.

** Psicóloga. Professora da Faculdade de Psicologia da PUCRS nos Cursos de Graduação e Pós-Graduação em Psicologia. Doutora em Psicologia Clínica pela Universidade Livre de Berlim.

*** Psiquiatra pela UFRGS. Analista didata da SPPA. Professor Adjunto do Departamento de Psiquiatria e Medicina Legal da FAMED/UFRGS Coordenador do Programa de Pós-Graduação em Ciências Médicas: Psiquiatria da UFRGS.
}

canálise e na psicoterapia de orientação analítica, o que motiva um permanente estudo e aperfeiçoamento da sua aplicação prática.

A supervisão psicanalítica é abordada neste artigo do ponto de vista temático, já que se pode encontrar a revisão histórica na literatura em algumas publicações bastante abrangentes e consistentes como foram realizadas por $\mathrm{Ba}-$ lint ${ }^{1}$; Fleming e Benedek ${ }^{2}$; Jacobs, David e Meyer $^{3}$; Frawley-O’Dea e Sarnat ${ }^{4}$.

\section{REVISÃO DA BIBLIOGRAFIA}

A revisão bibliográfica sobre o tema dos fatores da supervisão psicanalítica que influenciam o ensino e o aprendizado da transferência e da contratransferência foi realizada nas seguintes bases de dados bibliográficos: MEDLINE, JOURLIT, LILACS, PSYCHOLIT. As palavras-chave utilizadas na busca foram: supervision, psychoanalysis, training, psychoanalytic education, psychodynamic psychotherapy, transference, countertransference.

Além das bases de dados, foram consultados livros, revistas não indexadas, trabalhos apresentados em eventos científicos disponí- 
veis em nosso meio e indicações de colegas, que abordavam o tema da supervisão.

Nessa revisão da bibliografia, foram incluídas referências sobre psicoterapia de orientação psicanalítica, também chamada psicoterapia dinâmica, pois, conforme refere Machado ${ }^{5}$, a supervisão em psicoterapia de orientação analítica é uma aplicação da supervisão psicanalítica. Quando considerados relevantes, também foram incluídos dados sobre a supervisão no ensino da psiquiatria.

\subsection{A DEFINIÇÃO DE SUPERVISÃO}

A supervisão costuma ocorrer com um terapeuta menos experiente (o supervisionando), apresentando um determinado material colhido de sua prática clínica a um outro terapeuta mais experiente (o supervisor). O supervisionando relata da forma mais aproximada possível o que transcorreu na sessão psicanalítica ou psicoterápica.

A supervisão é um processo de habilitação do candidato. Nesse sentido, a atitude do supervisor deve estimular, no supervisionando, o desenvolvimento de suas próprias habilidades. Uma das principais funções da supervisão é a de desenvolver no supervisionando a capacidade de perceber suas próprias dificuldades. Essa seria a forma de conquistar a independência, seguindo ele sozinho, através de sua autocrítica, o processo de aprendizagem ${ }^{6}$.

Laplanche e Pontalis $^{7}$ (p.497) referem-se à supervisão como sendo uma "psicanálise conduzida por um analista em formação e da qual presta contas, periodicamente, a um analista experimentado, que o guia na compreensão e direção do tratamento e o ajuda a tomar consciência de sua contratransferência".

A supervisão psicanalítica é, essencialmente, uma relação de ensino-aprendizagem. Entretanto, como qualquer relação bi-pessoal, pode despertar sentimentos, tanto no supervisionando quanto no supervisor, sendo que ambos podem utilizar essa relação para a satisfação de outras necessidades, o que fica na dependência das características pessoais de cada um $^{8}$.

\subsection{A SUPERVISÃO NO CONTEXTO DO ENSINO DA PSICANÁLISE}

A supervisão, formalmente, passou a fazer parte da formação psicanalítica por volta de 1920, através de Abraham, Eitingon e Simmel, que a introduziram no Instituto de Berlim². a cargo a supervisão era diferente daquele que analisava o candidato a psicanalista. O modelo de Berlim defendia a idéia de que seria conveniente um candidato poder observar mais de um analista em trabalho, ao passo que a escola húngara, representada por Sandor Ferenczi e Otto Rank, defendia a necessidade de aprofundamento do conhecimento do candidato sobre si mesmo, o que não seria possível pela superficialidade da relação criada no modelo de Berlim, pois o supervisor não teria condições de entender as origens das reações do analista em formação ${ }^{3}$.

No final da década de trinta, a maioria dos Institutos rejeitou o modelo húngaro. Porém, o reconhecimento da necessidade de investigação e exploração da contratransferência seguiu sendo levado em conta ${ }^{3,9}$.

Historicamente, a supervisão em psicanálise é, juntamente com a análise didática e os seminários teóricos, um dos pilares básicos do que comumente alguns autores denominam de tripé da formação (figura 1) de um psicanalista ${ }^{1,3,10,11}$. A esse tripé pode-se acrescentar o elemento institucional que se faz presente em todo o processo de treinamento e de aquisição da identidade de psicanalista que o candidato recebe ${ }^{12-14}$. É também no processo de convivência e inter-relação com os membros da instituição, com o pensamento, com os modelos, idéias e procedimentos éticos e morais que o candidato baliza sua experiência de aprendizado.

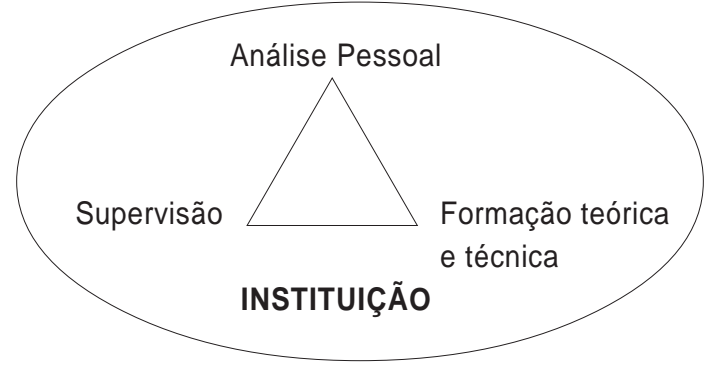

Figura 1. Modelo de aquisição da identidade: Tripé da formação psicanalítica ${ }^{11}$.

Vários autores já destacaram a importância da supervisão no processo de ensino-aprendizado tanto da técnica psicanalítica quanto da técnica da psicoterapia de orientação analítica: Arlow $^{15}$; De Bell ${ }^{16}$; Fleming e Benedek ${ }^{2}$; Grinberg $^{10,17}$; Solnit ${ }^{18}$; Gaoni e Neumann ${ }^{19}$; Blomfield ${ }^{20}$; Eizirik e Zaslavsky ${ }^{21}$; Szecsödy22,23; Eizirik ${ }^{24}$; Mabilde ${ }^{25}$; Soares ${ }^{26}$; Vollmer e Bernardi27; Brito $^{12}$; Zaslavsky ${ }^{28,29,30}$.

Pérez, Krul e Kapoor ${ }^{31}$ destacam que $98 \%$ 
dos residentes em psiquiatria no Canadá consideraram que a supervisão é altamente importante no desenvolvimento de suas habilidades psicoterapêuticas. Cataldo Neto et $\mathrm{al}^{32}$ observaram que $88,5 \%$ dos psiquiatras formados na Pontifícia Universidade Católica do Rio Grande do Sul (PUCRS) em duas décadas realizam ou realizaram supervisão durante uma média de seis anos, reforçando a importância da supervisão no treinamento e desenvolvimento de habilidades psicoterapêuticas.

A revisão da literatura sobre supervisão psicanalítica mostra uma escassez de bibliografia específica, ainda mais quando tentamos focalizar o estudo nos fatores que influenciam o ensino e o aprendizado da técnica. O estabelecimento de uma aliança de trabalho num enquadre adequado, as múltiplas funções do supervisor, o referencial teórico, os traços de caráter de ambos, o relacionamento entre supervisor e supervisionando e a natureza cognitivo-afetiva do processo de supervisão têm sido alguns dos elementos apontados e discutidos como potencialmente influenciadores no ensino-aprendizado da técnica através da supervisão psicanalítica ${ }^{2,27,33}$. No entanto, ainda parece impreciso como estes e outros elementos podem influenciar no aprendizado da técnica, principalmente da transferência e da contratransferência.

Freud, em diversas etapas de sua obra ${ }^{34-38}$, discorre sobre as sérias dificuldades em lidar com a transferência, pois via a mesma, inicialmente, como obstáculo e expressão das resistências do paciente. Considerava a transferência o mais importante instrumento terapêutico, que por um lado era "uma necessidade inevitável", e por outro, "era de longe, a parte mais árdua de toda tarefa" 35 (p.113), representando muitas vezes um verdadeiro fardo. A transferência, segue até hoje sendo um dos elementos mais importantes da técnica, ao mesmo tempo em que é temida pelo psicanalista, como menciona Grinberg ${ }^{39}$. Este autor salienta que, devido à percepção de que "a transferência é uma carga potencialmente perigosa" (p.11), o psicanalista procura se proteger dela com racionalizações teóricas e técnicas que resultam de operações defensivas. Talvez se possa fazer as mesmas considerações sobre a contratransferência.

A compreensão e a utilização da transferência e da contratransferência são destacadas por diversos autores como elementos essenciais na aplicação da técnica psicanalítica, portanto, merecem especial atenção na supervisão $0^{5,14,24,28,29,39-42}$. No entanto, a inclusão, o método de abordagem no ensino e no aprendizado da transferência e da contratransferência e as dificuldades surgidas na supervisão têm sido objeto de reflexão e de estudos recentes, gerando discussões e controvérsias por parte de estudiosos da psicanálise.

\subsection{MODELOS E FASES DA SUPERVISÃO}

Existe na bibliografia específica uma recorrente polarização entre duas atitudes na supervisão, uma chamada de didática e outra experiencia $^{R, 43}$. Na primeira, o supervisor age estritamente como professor que pode explicar, corrigir, sugerir, tornando-se um modelo para uma identificação por parte do supervisionando. As situações afetivas são lidadas exclusivamente no tratamento pessoal do candidato, conforme Abuchaim ${ }^{43}$. Já na atitude experiencial, esse autor refere que a função do supervisor é facilitar o crescimento pessoal do supervisionando. Problemas em aprender, compreender suas próprias reações com os pacientes e com o supervisor são tratados com o próprio supervisor. As reações contratransferenciais com os pacientes e com o supervisor são elaboradas na própria supervisão.

A partir das contribuições de Fleming e Benedek $^{2}$, Ekstein e Wallerstein ${ }^{44}$, Mabilde ${ }^{45}$, Vollmer Filho ${ }^{46}$ pode-se descrever, basicamente, três modelos metodológicos de supervisão (quadro 1) e, para fins didáticos, agrupá-los da seguinte forma:

1. Modelo Demonstrativo ou Clássico: corresponde a uma constante demonstração da técnica pelo supervisor, que transmite conhecimentos e procura mostrar, em suas intervenções, como ele conduziria a análise e que interpretações formularia. Este modelo é centrado no paciente.

2. Modelo Corretivo ou Comunicativo: apóia-se no modelo anterior, mas o supervisor faz correções, momento a momento, às intervenções, ao entendimento do supervisionando, apontando os seus erros e acertos. O material deve ser trazido mais detalhadamente pelo supervisionando, e os aspectos inconscientes deste são valorizados, mas a tarefa de modificá-los é deixada espontaneamente para o tratamento pessoal. Este modelo é centrado no supervisionando.

3. Modelo Compreensivo, Relacional ou Experiencial: o supervisor participa na experiência de aprendizagem do supervisionando em um nível empático, usa a si mesmo como instrumento para desenvolver, no candidato, as 
Quadro 1: Modelos Metodológicos de Supervisão

\begin{tabular}{|c|c|c|c|}
\hline \multirow{2}{*}{ MODELOS } & \multicolumn{3}{|c|}{ DESCRIÇÃO DOS MODELOS } \\
\hline & Supervisionando & Supervisor & Focalização \\
\hline $\begin{array}{l}\text { Clássico ou } \\
\text { Demonstrativo }\end{array}$ & $\begin{array}{l}\text { - Apresenta o material } \\
\text { para o supervisor. }\end{array}$ & $\begin{array}{l}\text { - Demonstra } \\
\text { constantemente a técnica. } \\
\text { - Transmite conhecimentos. } \\
\text { - Mostra em suas intervenções } \\
\text { como conduziria a análise e as } \\
\text { interpretações que formularia. }\end{array}$ & $\begin{array}{l}\text { Centrada no } \\
\text { paciente. }\end{array}$ \\
\hline $\begin{array}{l}\text { Corretivo ou } \\
\text { Comunicativo }\end{array}$ & $\begin{array}{l}\text { - Apresenta o material } \\
\text { mais detalhadamente. } \\
\text { - Valorização dos } \\
\text { aspectos inconscientes. } \\
\text { - Seus aspectos } \\
\text { inconscientes são levados } \\
\text { espontaneamente para a } \\
\text { análise pessoal. }\end{array}$ & $\begin{array}{l}\text { - Apóia-se no modelo clássico. } \\
\text { - Faz correções momento à } \\
\text { momento às intervenções } \\
\text { e ao entendimento. } \\
\text { - Aponta erros e acertos. } \\
\text { - Valoriza os aspectos } \\
\text { inconscientes, mas deixa o } \\
\text { supervisionando levar } \\
\text { espontaneamente para } \\
\text { sua análise. }\end{array}$ & $\begin{array}{l}\text { Centrada no } \\
\text { supervisionando. }\end{array}$ \\
\hline $\begin{array}{l}\text { Compreensivo, } \\
\text { Relacional ou } \\
\text { Experencial }\end{array}$ & \multicolumn{2}{|c|}{$\begin{array}{l}\text { - O supervisor participa da experiência de aprendizagem } \\
\text { do supervisionando em nível empático. } \\
\text { - O supervisor usa a si mesmo como instrumento para } \\
\text { desenvolver no supervisionando as funções essenciais } \\
\text { de analista. } \\
\text { - Observação da interação supervisor-supervisionando } \\
\text { como forma de entender o paciente. } \\
\text { - Transferência e contratransferência são abordadas } \\
\text { diretamente na supervisão. } \\
\text { - O supervisor aponta o quê e quando o supervisionando } \\
\text { deve levar para sua análise. }\end{array}$} & $\begin{array}{l}\text { Centrada na } \\
\text { interação } \\
\text { da dupla. }\end{array}$ \\
\hline
\end{tabular}

Zaslavsky; Nunes e Eizirik

funções essenciais do analista, leva em conta o que se passa na dupla supervisor-supervisionando como forma de entender o material do paciente e abordar a transferência e a contratransferência diretamente. Quando necessário, aponta o que o supervisionando deverá levar para seu tratamento pessoal. Este modelo é centrado na interação da dupla.

$\mathrm{Na}$ prática, os três modelos são complementares; entretanto, nos últimos anos, observa-se uma tendência de predomínio do modelo chamado de Experiencial. Tal tendência parece estar relacionada com a crescente influência da maior valorização dos fenômenos que ocorrem no campo psicanalítico, da utilização da relação transferência/contratransferência e conseqüente da valorização dos aspectos interacionais do par analítico.

Mabilde $^{45}$ propõe um quarto modelo, o da escuta multidirecionada, na qual "o processo de escuta do supervisor envolve, através da atenção flutuante, a participação e respectiva decodificação simbólica da totalidade dos personagens e de suas personalidades totais imbricados em sua prática, no presente e no passado" (p.4).

O processo de supervisão desenvolve-se em três períodos: inicial, intermediário e final $2,3,17,47,48$.

No período inicial, é importante para a experiência do supervisionando: a) escutar com atenção flutuante; b) aprender a inferir interpretações do significado latente, mas ainda sem formulá-las, ou seja, desenvolver a função integrativa; c) aprender a avaliar o grau de resistência e ansiedade que seu paciente apresenta e desenvolver a empatia com o estado regressivo deste (função sensitiva); d) formular intervenções, ainda que de forma, predominantemente, imitativa.

No segundo período, os objetivos são: a) julgar o momento e a dosagem das respostas e intervenções; b) captar o mais profundamente possível as reações transferenciais e contra- 
transferenciais.

$E$, finalmente, no terceiro período, ou fase final, a meta é: a) reconhecer as linhas dinâmicas e as mudanças de sessão para sessão; b) reconhecer o insight, a elaboração e a possibilidade de terminação. Pode ser acrescentado a este terceiro estágio o incremento da autonomia, independência em relação ao supervisor e expressão de maior capacidade criativa.

A visão de fases da supervisão (quadro 2) é, como salienta $\mathrm{Cruz}^{47}$, um exercício de sistematizar artificialmente - com finalidades didáticas ou de exposição - um processo que é contínuo e que apresenta inúmeras variáveis.

\subsection{SUPERVISÃO E A TÉCNICA PSICANALÍTICA}

Revisando a bibliografia, observa-se que ainda existem muito poucos estudos que sistematizam sobre como, quando e o quanto o supervisor pode ensinar e o supervisionando pode apreender a técnica psicanalítica e, mais especificamente, a transferência e a contratransferência. Embora a supervisão seja utilizada em praticamente todas instituições de treinamento em psicanálise e psicoterapia de orientação analítica, ela é pouco pesquisada de forma sistemática.

Diversos autores enfatizam sérias dificuldades metodológicas. A primeira delas é como coletar material para estudo. São usados: transcrições de suas próprias sessões de supervisão gravadas, dados de entrevista com supervisores, supervisionandos e mesmo pacientes, gravações de sessões de supervisões em ví- deo ou ainda notas do próprio supervisor sobre suas supervisões ${ }^{22}$.

Fleming e Benedek ${ }^{2}$ utilizaram-se de gravações de sua própria atividade como supervisores, na tentativa de estabelecer os diversos passos do processo de supervisão. Sua preocupação centrou-se na discriminação entre aprender e ensinar, concluindo que a teoria de supervisão deveria, primariamente, ser uma teoria de ensino, antes do que de aprendizado. Concluem que os procedimentos de ensino são adotados intuitivamente, baseados na experiência clínica de cada supervisor.

Os principais achados desses estudos demonstram que a escolha do que vai ser ensinado pelo supervisor depende muito de sua própria experiência clínica, sensibilidade e intuição. Também demonstram que ocorrem processos paralelos ou ressonância neurótica na supervisão em um grande número de casos, em que o supervisionando repete com o supervisor as transferências desenvolvidas pelo seu próprio paciente na sessão terapêutica ${ }^{22}$.

Para Brito ${ }^{12}$, uma das fortes motivações de alguém desejar supervisionar é justamente a possibilidade de elaborar experiências emocionais profundas (originárias tanto do paciente como do supervisionando e mesmo da interação supervisor-supervisionando) nesse ambiente relativamente controlado e facilitador de processos de elaborações freqüentes, ainda que parciais. Este autor realizou pesquisa qualitativa entrevistando supervisores e supervisionandos, buscando compreender como se dá a transmissão do conhecimento psicanalítico através da supervisão. A análise temática do

Quadro 2: Fases da Supervisão

FASES OBJETIVOS DA SUPERVISÃO

a) escutar com atenção flutuante;

b) aprender a inferir interpretações do significado latente, mas ainda sem formulá-las, ou seja, desenvolver a função integrativa;

Inicial

c) aprender a avaliar o grau de resistência e ansiedade que o paciente apresenta e desenvolver a empatia com o estado regressivo deste (função sensitiva)

d) formular intervenções, ainda que de forma, predominantemente, imitativa.

a) julgar o momento e a dosagem das respostas e intervenções;

Intermediária b) captar o mais profundamente possível as reações transferenciais e contratransferenciais.

Final $\quad$ a) reconhecer as linhas dinâmicas e as mudanças de sessão para sessã

c) incrementar a autonomia, independência em relação ao supervisor e expressão de maior capacidade criativa.

Zaslavsky; Nunes e Eizirik 
material resultou em três categorias finais: a) 0 contexto constitutivo da supervisão; b) O relacionamento interpessoal entre supervisor e supervisionando; c) $O$ processo ensino-aprendizagem desenvolvido durante a supervisão, bem como suas vicissitudes.

Dentre os resultados obtidos destacam-se: a) a supervisão psicanalítica é vista como um processo de ensino-aprendizagem; b) o processo de supervisão está permeado, influenciado, vinculado e até certo ponto determinado pela vida institucional; c) há intenso envolvimento emocional e interpessoal, mobilizando sentimentos conscientes e inconscientes, tanto em supervisores quanto em supervisionandos; d) tanto supervisores quanto supervisionandos ressaltam a importância fundamental do estilo pessoal do supervisor, seu jeito de trabalhar na supervisão, como elemento destacado no processo de ensino-aprendizagem na supervisão.

$\mathrm{Na}$ literatura revisada, parece não haver controvérsias quanto ao objetivo didático de uma supervisão. No entanto, surgem divergências entre os supervisores quanto ao estilo de trabalho e variações de abordagens da transferência e da contratransferência no processo.

Uma das questões mais polêmicas a respeito da supervisão é sobre as fronteiras entre a supervisão e tratamento psíquico ${ }^{24,28}$. A tendência observada na bibliografia específica sobre supervisão psicanalítica é a favor de que o analista e o supervisor sejam pessoas diferentes, seguindo a tradição da escola berlinense (também referida como escola vienense). No entanto, esse tema ressurge a cada situação em que o trabalho torna-se limitado frente aos conflitos emocionais que emergem durante o processo de supervisão, interferindo em seu sucesso.

Lebovici ${ }^{49}$ chama a atenção para um tema muito importante: o deslocamento do material transferencial da análise pessoal (didática) para a supervisão, levando a dissociações (analista visto como mau, supervisor como bom, ou viceversa); a idealizações (o supervisor é o máximo, ou o analista é o máximo) e ao uso defensivo e resistencial da supervisão no processo da análise pessoal.

Um estudo mais direcionado ao impacto causado pela supervisão sobre o processo terapêutico é o de Gross-Doehrman ${ }^{50}$. A questão proposta é: como a supervisão de um terapeuta estudante pode afetar e refletir-se em outro processo clínico em andamento, a psicoterapia de pacientes adultos? Enfatiza as reações emocionais do supervisor ao supervisionando, uma vez que tais reações podem provir de comuni- cações conscientes e/ou inconscientes do supervisionando, atuadas na supervisão, a partir de identificações com aspectos, desejos e/ou defesas do paciente. Sugere, dessa forma, a existência de processos paralelos em que os problemas do paciente com o terapeuta refletem-se através de problemas entre supervisionando e supervisor. A resolução dessas reações, com sua conotação neurótica, e, portanto, deletéria para a aquisição de insight, produz crescimento no supervisionando e é terapêutica para o paciente.

Rubinstein ${ }^{51}$ descreve os aspectos de sobreposição que podem ocorrer entre um processo de supervisão e uma terapia. Destaca o paralelo entre o insight e o crescimento pessoal, objetivos do processo terapêutico, com a autoconsciência e crescimento profissional, objetivos de uma supervisão, pois eles não estão totalmente separados. Também destaca as dificuldades na relação supervisor/supervisionando como similares àquelas que ocorrem durante o processo terapêutico, particularmente as decorrentes de processos paralelos. Além disso, refere que o desenvolvimento profissional do supervisionando é um processo emocional que requer identificação, reconhecimento e elaboração de emoções e atitudes, semelhante a uma relação terapêutica.

Outras semelhanças referem-se, ainda, à resistência à mudança que ocorre tanto em terapia como em supervisão, bem como o desenvolvimento natural de aspectos transferenciais e contratransferenciais em ambas as tarefas. Porém, o autor em questão ressalta as diferenças entre terapia e supervisão: a quantidade de informação sobre a vida pessoal do supervisionando é muito menor do que a obtida sobre a de um paciente; também o nível de profundidade da interpretação das motivações do supervisionando é muito menor do que num tratamento; e finalmente, e possivelmente o maior sinalizador de diferenças, refere-se aos objetivos de uma supervisão, que são diferentes dos objetivos de uma terapia. Enquanto a supervisão visa a propiciar o desenvolvimento de habilidades específicas, a terapia procura a resolução de conflitos e uma homeostasia psíquica mais global.

Os autores, em nosso meio, se alinham à visão de que a supervisão é um processo de ensino-aprendizagem e que as intervenções do supervisor preferentemente propiciem a relação aluno-professor $5,8,24,46,52,53$. No entanto, não excluem a percepção dos conflitos intrapsíqui$\cos$ e situações contratransferenciais, trabaIhando com esse material, não para investigar e 
tratar o supervisionando, mas sim dirigindo-o para o vértice de observação do que isso represente na relação transferencial do paciente com o supervisionando $0^{5,21,28,52}$.

Grinberg ${ }^{42}$, estudioso do tema há vários anos, compartilha dessa posição e alerta para a necessidade do supervisor e supervisionando ficarem atentos para a formação de processos paralelos na supervisão que podem levar a distorções.

\subsection{FATORES QUE INFLUENCIAM O PROCESSO DE SUPERVISÃO}

Com base na revisão realizada, pode-se sistematizar os fatores mais citados na literatura, que influenciam o processo de ensino e aprendizado através da supervisão, conforme consta no quadro 3.

Quadro 3: Fatores que influenciam o processo de supervisão psicanalítica

1. O processo ensino-aprendizado como sendo de natureza cognitivo-afetiva.

2. As múltiplas funções do supervisor como: modelo de identificação e valores ético, guardião do processo ${ }^{27,28}$.

3. O desenvolvimento de uma aliança de aprendizado $^{2}$, também chamada de aliança funcional ${ }^{27}$.

4. A caracterização de um enquadre: incluindo um contrato (verbal) explicitando a forma de trabalho, além de horários, honorários, redação das sessões dialogadas, com cópia para ambos, etc.

5. O relacionamento entre supervisor e supervisionando: motivação, empatia e afetividade.

6. O referencial teórico do supervisor.

7. Os traços de caráter de ambos.

8. A capacidade intuitiva de ambos.

9. A abordagem da transferência e da contratransferência.

10. Os modelos e as fases da supervisão

Zaslavsky; Nunes e Eizirik

É essencial pensarmos que o processo de ensino-aprendizado é de natureza cognitivoafetiva ${ }^{27,33,46}$. Este parece ser um consenso: 0 ensino e o aprendizado da técnica psicanalítica são influenciados por fatores de ordem cognitiva e afetiva. Tal divisão parece ser meramente didática, pois na prática ambos aparecem mesclados, embora em alguns momentos, um ou outro elemento possa predominar.

A supervisão tem como objetivo auxiliar o supervisionando a estabelecer as bases para a aquisição da identidade de psicanalista. Essa identidade é construída a partir da transmissão de conhecimentos, dos procedimentos técnicos e do estímulo constante ao desenvolvimento da capacidade de transformar conhecimentos teóricos em intervenções interpretativas no processo psicanalítico. Ocorre que neste relacionamento existem projeções, identificações e identificações projetivas entre supervisionando, supervisor, paciente e, eventualmente, com o próprio analista do supervisionando. Bion ${ }^{54}$ considera o aprender a partir da experiência como essencial no desenvolvimento de uma experiência emocional capaz de produzir mudanças comportamentais. Assim, se a supervisão é bem sucedida (não havendo transgressões), o supervisionando introjeta modelos éticos e técnicos, conhecimentos teóricos aplicados ao material apresentado, que resultarão em mudanças internas através de processos de identificação, promovendo o crescimento e desenvolvimento da identidade psicanalítica e da personalidade.

A formação de uma identidade psicanalítica é um dos objetivos primordiais do treinamento de um analista e, nesse sentido, a tarefa de supervisão é fundamental ${ }^{55,56}$. A internalização de diferentes modos de funcionamento, através da supervisão, é destacada por supervisores e supervisionandos, como um dos elementos essenciais para a aquisição da identidade psicanalítica ${ }^{57}$.

Para que as identificações possam ocorrer de modo desejável e se formar uma identidade, é necessário que a supervisão tenha uma estrutura estável de funcionamento.

Parodiando a afirmação de Meltzer ${ }^{58}$, ao se referir ao processo psicanalítico - o psicanalista deve ser o "guardião do setting"58 (p.32) - Zaslavsky $^{28}$ (p.130) propõe que o analista seja o "guardião do processo de supervisão", o que inclui o cuidado que o supervisor deve ter em manter o sigilo, em não ser diretivo e autoritário, a fim de não comprometer a liberdade e a responsabilidade do supervisionando ${ }^{59}$. É fundamental que se desenvolva uma "aliança de aprendizado" (expressão utilizada por Fleming e Benedek ${ }^{2}$ [p.53]) entre supervisor e supervisionando. Para que isto se desenvolva de uma forma adequada, faz-se necessário que o supervisor tenha em mente as múltiplas funções que pode vir a exercer durante o relacionamento com seu supervisionando ${ }^{27}$.

As múltiplas funções, conforme Vollmer Fi- 
Iho e Bernardi ${ }^{27}$ e Szecsödy ${ }^{33}$, podem ser resumidas em: a) gerir o processo de supervisão, b) atuar como modelo de identificação, c) ensinar procedimentos técnicos, d) transmitir conhecimentos teóricos e e) representar a instituição à qual pertence. Supervisor e supervisionando devem estabelecer uma aliança funcional, lembrando que seus objetivos devem respeitar os interesses do paciente, que poderão colidir em algum momento com os interesses do supervisionando, do analista do supervisionando quando estiver em tratamento e com o próprio supervisor. Reside aí uma questão importante que é a abordagem da contratransferência durante a supervisão, a qual será mencionada mais adiante.

As funções do supervisor podem ser resumidas, segundo Szecsödy ${ }^{22}$, em: 1) incentivar a aliança de aprendizagem para apoiar o desejo e a ambição de aprender do supervisionando; 2) manter um setting de trabalho; 3) compreender o supervisionando e fazer-se compreensível para ele; 4) identificar o conflito principal do material e formular hipóteses compreensíveis; 5) auxiliar o supervisionando a reconhecer a resistência e a transferência na interação com o paciente, bem como reconhecer suas manifestações contratransferenciais; e, por fim, 6) reconhecer suas próprias reações contratransferenciais em relação ao supervisionando.

Como foi mencionado, o modelo de aprendizado por identificação pode sofrer desvios ou distorções. Nesta linha, pode ocorrer uso maciço de identificação projetiva, baseado na fantasia onipotente do supervisionando de ter acesso às qualidades e habilidades do supervisor e tomar posse delas. Este caminho conduz à limitação da percepção do supervisionando em relação ao supervisor, resultando em uma identificação distorcida. As atitudes imitativas, que predominam no comportamento inicial do supervisionando, fazem parte do processo natural de identificação com o supervisor. Entretanto, quando as atitudes do supervisionando são puramente imitativas e, portanto, pseudo-analíticas, o crescimento fica limitado e empobrecido. Como salienta Vollmer Filho e Bernardi ${ }^{27}$, é mister que se possa diferenciar o verdadeiro aprendizado por identificação do imitativo.

Uma terceira possibilidade de aprendizado pode estar baseada na identificação projetiva com um objeto interno idealizado ${ }^{27}$. Quando a relação ensino-aprendizado idealizada predomina, a atitude do supervisionando é marcada por uma fantasia de onisciência e onipotência com manifestações de arrogância, nitivo e absoluto. Nestes casos, ocorre pouco crescimento.

Além da função de ensinar procedimentos técnicos e teóricos, o supervisor inclui nesta transmissão de conhecimento aspectos do seu modelo ético e do seu caráter, que também influenciam o estilo de supervisão. O predomínio ou a presença significativa de características narcisísticas, sadomasoquistas ou paranóides, tanto no supervisor quanto no supervisionando, pode prejudicar a situação de aprendizado. O referencial teórico, bem como seu modo de compreendê-lo e interpretá-lo, orienta os rumos da supervisão ${ }^{27}$.

O supervisor, ao expor seu estilo e o modo de interpretar, demonstra como funciona sua mente, ajudando o supervisionando a ir desenvolvendo o seu próprio modelo de entendimento das fantasias inconscientes e seu estilo interpretativo independente e criativo. Cabe ao supervisor mostrar como essas fantasias são atualizadas em termos de conflito atual na transferência e ficar atento às diversas possibilidades de apresentação dos sentimentos contratransferenciais, pois a abordagem da transferência e da contratransferência pode ampliar a compreensão do caso em questão, com mencionam $24,27,28,42$.

O entendimento da transferência e da contratransferência é uma importante via de compreensão das relações de objeto e do mundo interno do paciente, que normalmente são observadas através dos padrões de relacionamento estabelecido pelo paciente com seu psicanalista. Essas flutuações no relacionamento, que podem ser desde manifestações sutis até mais grosseiras, também são focos, ao lado das expressões verbais e comportamentais, de observação da dupla supervisor/supervisionando para o entendimento do caso em estudo.

Assim como as relações de objetos internos expressam-se na relação interpessoal entre paciente e psicanalista (expressão da transferência), também o padrão de relacionamento entre supervisionando e supervisor pode ser influenciado por derivados do campo transferencial dos tratamentos supervisionados. Trata-se de identificações projetivas provenientes do paciente, resultantes de sua conflitiva interna inconsciente que, quando não elaboradas e compreendidas pelo psicanalista, podem ser atuadas na relação com o supervisor como forma de comunicação inconsciente. Esses eventos, que foram, originalmente, chamados por Searles $^{60}$ (p.135) de processos paralelos, geralmente se manifestam através da apresentação do material ou de quebras do enquadre da su- 
pervisão.

Por isso, diversos autores $2,10,17,24,25,28,29$ salientam a importância e a utilidade de o supervisor estabelecer com o supervisionando um contrato (verbal) de supervisão, explicitando sua forma de trabalho, além de horários, honorários, redação das sessões dialogadas com cópia para ambos, caracterizando um enquadre de trabalho. Rupturas ou desvios desse enquadramento podem ser expressões desses processos paralelos que informam sobre conflitos não elaborados dentro da sessão analítica. São manifestações, muitas vezes sutis, como desde a falta à supervisão, atrasos, até a redação excessivamente detalhada ou muito resumida da sessão, falta de tempo para redigi-las, uso excessivo do tempo para conversar sobre outros assuntos de fora da supervisão, falta de entusiasmo para a tarefa de supervisão, insegurança na orientação do supervisor (de forma irrealística), e assim por diante. Tais elementos podem ser úteis na observação mais acurada e detalhada do caso supervisionado, no aprofundamento exploratório sobre as motivações provenientes do espaço analítico supervisionado (e não do mundo interno do supervisionando) e para efetuar-se a validação do processo de supervisão.

As manifestações transferenciais podem ser diretas ou indiretas (através da cadeia associativa do paciente) e poderão ser identificáveis durante a sessão, ou então, durante a redação do material para a supervisão, ou ainda, surgirem durante a própria supervisão. Em qualquer uma das situações, pode-se examinar com o supervisionando as razões de tal ocorrência. É freqüente, por exemplo, que um terapeuta inexperiente perceba o material transferencial na hora de dialogar a sessão. Isto pode indicar um potencial do supervisionando para ir apreendendo a perceber e entender a transferência. O supervisor também poderá, quando julgar necessário, indicar ao supervisionando alguma bibliografia para leitura, tanto sobre técnica quanto sobre teoria. Por outro lado, também podem surgir dificuldades quando o supervisionando resiste em aceitar ou entender o material transferencial que lhe é mostrado. Não raro observa-se a reprodução na relação de supervisão do que está se passando no tratamento. Nestes casos, Eizirik ${ }^{24}$ alerta para o risco de, ao se discutir esse aspecto, transformar a supervisão em tratamento. Mostrar algum exemplo semelhante em que o supervisor incorreu no mesmo erro pode ser bem mais produtivo e diminuir a resistência.

Dentro do modelo experencial/relacional, a contratransferência no processo supervisório deve ser francamente discutida, como mais um instrumento de trabalho ${ }^{21}$. Esta tarefa é facilitada quando o supervisionando está em tratamento pessoal. É mister que se tenha clara a noção de limites, ou seja, não cabe ao supervisor investigar ou interpretar as origens dos sentimentos do terapeuta, e sim utilizá-los para compreender o paciente, na medida em que sejam despertados na análise ou que surjam na supervisão. A escolha do que vai ser abordado pelo supervisor e o modo de fazê-lo depende muito de sua própria experiência clínica, sensibilidade e intuição.

Devido à possibilidade de aspectos da personalidade do supervisionando entrarem em cena e do risco da supervisão se transformar em tratamento, vários autores recomendam que o supervisionando esteja em tratamento pessoal quando forem abordados os sentimentos contratransferenciais ${ }^{61,62,63}$.

Quando a contratransferência é trazida diretamente pelo supervisionando, pode revelar um aumento de confiança no trabalho de supervisão. Deve-se mostrar que aspectos estão projetados dentro do terapeuta, relacionando-os com a compreensão do caso. Quando a contratransferência é percebida só pelo supervisor, sua abordagem pode ser mais complexa. Nestes casos, pode-se sugerir que o supervisionando fique mais atento aos seus aspectos emocionais, além de o supervisor fornecer algum exemplo pessoal em que também surgiram manifestações contratransferenciais ${ }^{28,24,40}$.

Para estes autores, deve ficar sempre transparente a distinção entre supervisão e tratamento pessoal. Neste sentido, a atenção do supervisor como guardião do processo parece essencial. É recomendável ao supervisor, quando julgar necessário, indicar que aspectos pessoais sejam levados ao local mais apropriado, mantendo-se ambos dentro do limite mencionado. Como regra geral, parece-nos prudente que a abordagem da contratransferência parta do supervisionando, o que freqüentemente ocorre quando o clima da supervisão é predominantemente de franqueza e baseado numa aliança de trabalho.

Rocha $^{64}$, abordando a supervisão do ponto de vista do supervisionando, conclui que entre as razões de impasse na supervisão mais freqüentemente estão: a divergência de orientação teórica, a persistência de ansiedades paranóides, a não compreensão da contratransferência, a persistente repetição de processos paralelos e quando o supervisionando não está em tratamento. 


\subsection{O PROCESSO DE SUPERVISÃO}

Frijling-Schreuder ${ }^{65}$ refere que é conveniente criar uma "aliança de trabalho" (p.374), pois diferencia da situação analítica e estimula a regressão no setting de supervisão. Esta aliança de trabalho pode ter várias linhas de desenvolvimento, começando com insegurança e dependência por parte do aluno, que, na medida em que aumenta sua capacidade de entender o material do paciente e de compreender o processo analítico, vai modificando sua atitude na supervisão, chegando a se estabelecer, entre supervisor e supervisionando, um diálogo adulto e profissional. Esse autor salienta alguns pontos que merecem a atenção do supervisor: capacidade de empatia, sensibilidade para o material inconsciente, manejo da transferência e da contratransferência.

No aspecto contratransferencial, FrijlingSchreuder ${ }^{65}$ chama a atenção para as reações que são esperadas e normais de supervisionandos iniciantes e para as quais o mais importante é que o supervisor tenha paciência. Em contraposição, podem ocorrer reações mais fixas e estruturadas, que persistem durante o trabalho de supervisão sem modificações, indicando distúrbios neuróticos. Como recomendam Eziirik e Zaslavsky ${ }^{21}$; Ezirik ${ }^{24}$; Zaslavsky ${ }^{28}$, o supervisor deve estar atento para as manifestações de:

1. sentimentos paranóides no supervisionando, que podem variar conforme os traços de personalidade, o estágio de formação profissional e que podem se acentuar em situações de avaliação;

2. a baixa tolerância quando o supervisionando não sabe o que fazer com o paciente devido à falta de conhecimentos e experiência. Muitas vezes, esta intolerância pode ser uma defesa contra ansiedades depressivas e sentimentos de desvalorização, pelo medo de perder o paciente, o amor do supervisor e por ameaças à própria carreira quando estiver ligado a uma instituição. O relacionamento do supervisor com o supervisionando pode ajudá-lo a tolerar tais ansiedades, enfrentando as frustrações e o desconhecido, através da capacidade de ser continente, como recomenda Bion ${ }^{66}$;

3. a formação de "ponto cego" em função das identificações inconscientes do supervisionando como paciente. É necessário distinguir aquelas identificações que são úteis ao processo e, portanto, transitórias, daquelas que se cristalizam e impossibilitam o manejo e levam ao "acting";
4. o processo de luto. O supervisionando sofre uma ferida em seu narcisismo ao reconhecer suas limitações e pouca experiência. A identificação com os aspectos funcionais do supervisor, desenvolvendo uma capacidade de auto-supervisão, pode ser comparada a um luto bem sucedido. Por outro lado, à medida que 0 supervisionando progride, como em qualquer outra relação de aprendizagem, o supervisor terá que aceitar e elaborar o luto pela perda de uma relação inicialmente idealizada. As estruturas de personalidades muito narcisísticas (do supervisor) poderão encontrar dificuldade em aceitar e tolerar a progressiva independização do supervisionando, que vai ampliando gradualmente sua capacidade de pensar com mais liberdade e criatividade, até mesmo discordando da opinião do supervisor.

Outro aspecto a ser lembrado é a possível utilização da supervisão como "acting out" ou "acting in", ou seja, uma forma do supervisionando tentar obter gratificações do supervisor as quais não obtém em seu tratamento pessoal. Deve o supervisor ficar atento às eventuais situações e tentativas do supervisionando em transformar a supervisão em tratamento, pois, no nosso entender, este não é o propósito. A persistência dessa atitude bloqueia a análise pessoal do supervisionando, criando sérios problemas e ameaças à continuidade da supervisão. Nestas circunstâncias, é recomendável que o supervisionando procure levar tais aspectos para o seu tratamento pessoal, podendo isto ser sugerido pelo supervisor.

O supervisionando pode ter sentimentos variados em relação ao supervisor, tais como reações de admiração, ciúme, inveja, temor, hostilidade, etc. A maior capacidade do supervisor, em termos de experiência, pode inspirar sentimentos de admiração, idealização e inveja. O temor sentido pelo supervisionando é, muitas vezes, o resultado de sentir-se frente a uma autoridade investida de poderes para um julgamento que pode ser determinante de seu futuro profissional ${ }^{67}$.

Também o supervisor pode ter sentimentos inconscientemente ativados durante a situação de supervisão. Dentre esses, ele pode, por exemplo, assumir uma atitude onipotente, apresentando suas idéias como se fossem absolutas e inequívocas, ou utilizar-se da situação de supervisão para gratificar-se narcisicamente, valendo-se para isso do estímulo à relativa dependência e dos inevitáveis sentimentos de inferioridade do supervisionando ${ }^{60}$.

Shanfield, Mattews e Hetherly ${ }^{68}$, tratando 
do que ocorre no ensino psiquiátrico, examinaram as avaliações de supervisores e concluíram que os considerados excelentes: permitem ao residente desenvolver a apresentação de seu material sobre o encontro ou sessão com o seu paciente; identificam e focalizam o trabalho no ponto de maior preocupação e carga afetiva para o aluno; abordam sempre a experiência imediata do residente e o seu material clínico, que serve de base para a compreensão do caso; são disciplinados ao ensinar, centrando as digressões do residente no próprio caso; convidam o aluno a especular sobre os significados do material do paciente através de questionamentos abertos; raramente usam jargão técnico; sugerem intervenções ligadas a preocupações presentes no residente; procuram, com suas intervenções, ajudar o residente a entender mais profundamente as ações, os pensamentos e o modo como o paciente sente. Quando focam nas relações, fazem-no na relação transferencial e em como o paciente sente a terapia; dirigem menos freqüentemente suas observações para a compreensão do papel do residente na interação e quando o fazem identificam a fonte de ansiedade deste na relação com o paciente; recorrem à estratégia de utilização do processo paralelo para permitir uma compreensão mais profunda do paciente.

Como se pode observar, a presente revisão, que não se pretende completa nem capaz de apreender a complexidade do tema, colhe a experiência de diversos autores que têm contribuído para a construção de um conhecimento mais estruturado do processo de supervisão, dando ênfase ao trabalho produzido por vários analistas e psicoterapeutas de nosso meio. Mais recentemente, uma nova fonte de conhecimento tem surgido a partir de pesquisas qualitativas sobre a supervisão analítica, e é de se esperar que esses novos dados tragam mais elementos para que o mapeamento dessa fascinante área continue a ser desenvolvido.

\section{REFERÊNCIAS BIBLIOGRÁFICAS}

1. Balint M. On the Psychoanalytic Training System. The International Journal of Psychoanalysis, 1948; 29: 163-173.

2. Fleming J.; Benedek T. The Psychoanalytic Supervision. New York: Grune \& Stratton, 1966

3. Jacobs D.; David P.; Meyer DJ. The supervisory encounter: a guide for teachers of psychodynamic psychotherapy and psychoanalysis. New york: Yale University, 1995.

4. Frawley-O'Dea MG and Sarnat JE. Models of Supervision. In: - The supervision relationship. New York: The Guilford Press; 2001. p. 25-49.

5. Machado PM. Bases Teóricas. In.: MABILDE LC. (org.) Supervisão em Psiquiatria e em Psicoterapia Analítica: teoria e técnica. Porto Alegre: Mercado Aberto, 1991. p. 14-27.

6. Schlesinger HJ. General Principles of Psychoanalytic Supervision. In.: Wallerstein R.S. (Ed.). Becoming a Psychoanalyst. New York: International University Press, 1981.

7. Laplanche J.; Pontalis J.B. Vocabulário da Psicanálise. São Paulo: Martins Fontes, 1983. 7a Edição, 707p.

8. Pechansky I.: Vicissitudes da supervisão psicanalítica. Revista de Psicanálise da Sociedade Psicanalítica de Porto Alegre, 1996;3:295-298.

9. Grotjahn M. Problems and techniques in supervision. Psychiatry, 1955; 18: 9-15.

10. Grinberg L. The problems of supervision in psychoanalytic education. The International Journal of Psychoanalysis, 1970;51:371-383.

11. Zaslavsky J.; Brito CLS. Ensino de psicoterapia de orientação analítica. In: Psicoterapia de Orientação Analítica: Teoria e prática. Porto Alegre: Artes Médicas, 2003. Capítulo de livro a ser publicado.

12. Brito CLS. A transmissão do conhecimento psicanalítico através da supervisão. Porto Alegre. Tese (Mestrado em Psicologia Social e Personalidade), Faculdade de Psicologia, Pontifícia Universidade Católica do Rio Grande do Sul (PUCRS) 1999.

13. Kernberg $O$. Trinta métodos para destruir a criatividade dos candidatos a psicanalista. Livro Anual de Psicanálise, São Paulo: Escuta; 1996.12: 151-160.

14. Kernberg O. A Concern Critique of Psychoanalytic Education, International Journal of Psychoanalysis, 2000; 81:97-120.

15. Arlow JA. The supervisory situation. The Journal of the American Psychoanalytic Association 1963; 11: 576-94.

16. De Bell DE. A critical digest of the literature on psychoanalytic supervision. The Journal of the American Psychoanalytic Association 1963;11: 546-75.

17. Grinberg L. La Supervision Psicoanalitica: teoria y práctica. Buenos Aires: Paidos, 1975. 110p.

18. Solnit AJ. Learning from Psychoanalytic Supervision. The International Journal of Psychoanalysis, 1970;51:359-62.

19. Gaoni B.; Neumann M. Supervision from the point of view of the supervisee. Amer. J. Psychot. 1974; 28:108-14.

20. Blomfield OHD. Psychoanalytic supervision: an overview. The International Journal of Psychoanalysis 1985;12: 401-9.

21. Eizirik CL.; Zaslavsky J. Abordagem da contratransferência na supervisão da psicoterapia. In: Eizirik Cl.; Aguiar R.; Schestatsky S. et al. Psicoterapia de orientação analítica: teoria e prática. Porto Alegre: Artes Médicas, 1989. p. 296-304.

22. Szecsödy I. The Significance and Importance of Supervision in Psychotherapy Training. Psychotherapy and Psychosomatics, Zurique, 1990a;53:86-92.

23. Szecsödy I. The learning Process in Psychotherapy Supervision. Stockholm: Karolinska Institutet; 1990b. 221p.

24. Eizirik CL. Compreensão e manejo da transferência e da contratransferência. In.: Mabilde L.C. (org.). Supervisão em Psiquiatria e em Psicoterapia Analítica: teoria e técnica. Porto Alegre: Mercado Aberto, 1991. p.61-71.

25. Mabilde LC. Apresentação. In.: Mabilde LC. (org.). Supervisão em Psiquiatria e em Psicoterapia Analítica: teoria e técnica. Porto Alegre: Mercado Aberto, 1991a. p.9-11.

26. Soares PFB. Distorções na interação supervisor/supervisionando. In.: Mabilde, L.C. (org.). Supervisão em Psiquiatria e em Psicoterapia Analítica: teoria e técnica. Porto Alegre: Mercado Aberto, 1991. p. 95-101.

27. Vollmer Filho G.; Bernardi R. As funções múltiplas do supervisor, os seus relacionamentos com o supervisionando, o analista do supervisionando, o paciente, o qua- 
dro de referência teórico e a instituição de treinamento. Revista de Psicanálise da Sociedade Psicanalítica de Porto Alegre. 1996;3:283-93.

28. Zaslavsky J. Supervisão em psicoterapia de orientação analítica: o relacionamento do supervisor com o supervisionando e o manejo da transferência e da contratransferência. Revista Brasileira de Psicoterapia, Porto Alegre, 1999;1(1):129-37.

29. Zaslavsky J. Ensino de psicoterapia de orientação analítica: concepções atuais e seus desafios. Relatório apresentado na Mesa-Redonda sobre Ensino em Psiquiatria, no XX Congresso Brasileiro de Psiquiatria. 16-19 de outubro de 2002b. Florianópolis - SC.

30. Zaslavsky J. et al. Editorial. A história e os pressupostos ideológicos do Curso de Especialização em Psicoterapia de Orientação Analítica. Revista Brasileira de Psicoterapia, Porto Alegre, 2002a;4(supl):7-12.

31. Perez EL.; Krul LE.; Kapoor R. The Teaching of Psychotherapy in Canadian Psychiatric Residency Programs: Residents' Perceptions. The Canadian Journal of Psychiatry, Ottawa, 1984;29:658-664.

32. Cataldo Neto A. et al. Duas décadas de formação psiquiátrica na PUCRS: perfil dos psiquiatras formados. Revista de Psiquiatria do Rio Grande do Sul, Porto Alegre, 1995; 17:3, 201-209.

33. Szecsödy I. (How) Is learning possible in supervision? In: Martindale B. Supervision and its vicissitudes. Karnak Books: London; 1997. p.101-16.

34. Freud S. (1895). Estudos sobre a histeria. E.S.B. Rio de Janeiro, Imago. 1974.v.2,p.237-365

35. Freud S. (1905). Fragmento da análise de um caso de histeria. E.S.B. Rio de Janeiro, Imago, 1974. v.7, p.1119

36. Freud S. (1912). Dinâmica de transferência. E.S.B. Rio de Janeiro, Imago, 1974. v.12, p.131-59.

37. Freud S. (1920). Além do princípio do prazer. E.S.B. Rio de Janeiro, Imago, 1974. v.16, p.13-85.

38. Freud S. (1937). Análise terminável e interminável. E.S.B. Rio de Janeiro, Imago, 1975. v.23, p.241-87.

39. Grinberg L. A Transferência é temida pelo Psicanalista? IN: Livro Anual de Psicanálise. Editora Escuta. 1997; 13 p. 11-22

40. Eizirik CL.; Araújo MS. Compreensão e manejo da transferência em supervisão de análises de adultos. Revista de Psicanálise da Sociedade Psicanalítica de Porto Alegre, 1997; 4(1):13-20.

41. Gabbard G. Countertransference: The emerging common ground. Int. J. Psychoa-anal. 1995; 76 (3): 475-85.

42. Grinberg L. Consideraciones acerca de la transferência y la contratransferência en la supervisión. In: Grinberg L. El psicoanálisis es cosa de dos. Valencia: Promolibro, 1995.

43. Abuchaim CM. A relação ensino-aprendizagem em su pervisão de psicoterapia de orientação analítica. Porto Alegre, 1996. Trabalho apresentado na VII Jornada Paulo Guedes, Fundação Universitária Mário Martins.

44. Ekstein R, Wallerstein RS. The Teaching and Learning of Psychotherapy. New York: Basic Books, 1958.

45. Mabilde LC. Ensino em Psicoterapia: Escuta em supervisão. Trabalho apresentado na XIX Jornada Sul-rio-grandense de Psiquiatria Dinâmica, nov/1998.

46. Vollmer Filho G. Linhas teóricas e ideologia de formação. Recife, 1995. Trabalho apresentado no XV Congresso Brasileiro de Psicanálise.

47. Cruz JG. Fases da Supervisão. In.: MABILDE L. C. (org.) Supervisão em Psiquiatria e em Psicoterapia Analítica: teoria e técnica. Porto Alegre: Mercado Aberto, 1991. p. $53-62$.

48. Dewald PA. Learning Process in Psychoanalytic Supervision: Complexities \& Challenges. Madison: International
Universities Press, 1987

49. Lebovici S. Technical Remarks on the Supervision of Psychoanalytic Treatment. The International Journal of Psychoanalysis, 1970;50:385-92.

50. Gross-Doehrman MJ. Parallel Processes in Supervision and Psychotherapy. Bulletin of the Menninger Clinic, Topeka, 1976; I:9-105.

51. Rubinstein G. Supervision and psychotherapy: toward redefining the differences. The Clinical Supervisor 1992;10:97-116.

52. Mabilde LC. Supervisão do narcisismo ou narcisismo da supervisão. In.: Mabilde LC. (org.). Supervisão em Psiquiatria e em Psicoterapia Analítica: teoria e técnica. Porto Alegre: Mercado Aberto; 1991b. p.89-93.

53. Schestatsky SS. As intervenções do supervisor. In.: MABILDE, L.C. (org.). Supervisão em Psiquiatria e em Psicoterapia Analítica: teoria e técnica. Porto Alegre: Mercado Aberto; 1991. p.73-87.

54. Bion WR. (1962). O aprender com a experiência. IN: Os elementos da Psicanálise. Rio de Janeiro: Zahar; 1966. p.7-122.

55. Blum HP. On Identification and its Vicissitudes. Int. J. Psychoanal. 1986;67:267-276.

56. Rocha Barros EM.: Formação e transmissão da psicanálise. IDE, dez, 1986.

57. Rosito C. et al. Algumas reflexões sobre a supervisão do ponto de vista dos candidatos. Revista de Psicanálise da Sociedade Psicanalítica de Porto Alegre 1996; 3(2): 303309.

58. Meltzer D. (1967). El proceso psicoanalitico. Paidós: Buenos Aires; 1976.

59. Annes SP. (1996) Simposium sobre Supervisão. Relatório apresentado no Simpósio da SPPA.

60. Searles HS. The informational value of the supervisor's emotional experiences. Psychiatry 1955;18:135-46.

61. Gauthier M. Countertransference and supervision: a discussion of some dynamics from the point of view of the supervisee. Can. J. Psychiatry. 1984; 29:513-19.

62. Goin MK.; Kline F. Countertransference: a neglected subject in clinical supervision. Am. J. Psychiatry. 1976;133 (1):41-4.

63. Greben SE. The influence of supervision of psychotherapy upon being therapeutic: modes of influence of the supervisory relatioship. Can. J. Psychiatry. 1979; 24:50713.

64. Rocha NS. Supervisão em Psicoterapia de Orientação Analítica: a perspectiva de uma amostra de supervisores de Porto Alegre, Brasil, Revista Brasileira de Psicoterapia $2001 ; 3(3): 213-228$

65. Frijling-Schreuder ECM. On Individual Supervision. The International Journal of Psychoanalysis 1970;51:363-70.

66. Bion W. (1963) Os Elementos de Psicanálise. Rio de Janeiro: Zahar editores; 1966.

67. Machado SP. Objetivos e aspectos motivacionais. In. MABILDE L. C. (org.). Supervisão em Psiquiatria e em Psicoterapia Analítica: teoria e técnica. Porto Alegre: Mercado Aberto; 1991. p.29-37.

68. Shanfield SB.; Matthews KL.; HetherlY V. What do ExceIlent Psychotherapy Supervisors do? The American Journal of Psychiatry, New York: 1993;150: I081-1084.

\section{RESUMO}

A formação psicanalítica está alicerçada sobre três pilares básicos: a análise didática, os seminários teóricos e a supervisão clínica de análises. O modelo de supervisão psicanalítica, como um todo ou parte dele, é utilizado em diversas áreas do ensino da 
medicina, da psiquiatria e da psicologia, principalmente na psicanálise e na psicoterapia de orientação analítica, o que motiva um permanente estudo e aperfeiçoamento da sua aplicação prática. A presente revisão tem como finalidade tentar sistematizar aspectos da supervisão psicanalítica, visando a contribuir para uma área ainda em desenvolvimento, $e$ que conta com crescentes contribuições realizadas em nosso meio.

Descritores: Supervisão psicanalítica, supervisão de psicoterapia de orientação analítica, formação psicanalítica.

\section{ABSTRACT}

The psychoanalytic training is based on three basic pillars: the didactic analysis, the theoretical seminars and the clinical supervision of analyses. The psychoanalytic supervision model, has been used in several areas in medicine, in psychiatry and in psychology, mainly in the psychoanalysis and in the psychoanalytic psychotherapy. This fact motivates a permanent study and improvement of its practical application. The purpose of this review is to try to systematize aspects of the psychoanalytic supervision, to contribute an area still in development, and which has been a matter of interest and in our.

Keywords: Psychoanalytic supervision, psychoanalytic psychotherapy supervision, psychoanalytic training.

Title: Psychoanalytic supervision: a review and an approach to systematize

\section{RESUMEN}

La formación psicoanalítica está fundamentada sobre tres pilares básicos: la análisis didáctica, los seminarios teóricos y la supervisión clínica de análisis. El modelo de supervisión psicoanalítica, como un todo o parte de él, es utilizado en diversas áreas de la enseñanza de la medicina, de la psiquiatría y de la sicología, principalmente en el psicoanálisis y en la psicoterapia de orientación analítica, lo que motiva un permanente estudio y perfeccionamiento de su aplicación práctica. La presente revisión tiene como finalidad intentar sistematizar aspectos de la supervisión psicoanalítica, con el objetivo de contribuir para un área todavía en desarrollo, y que cuenta con crecientes contribuciones realizadas en nuestro medio.

Palabras-clave: Supervisión psicoanalítica, supervisión de psicoterapia de orientación analítica, formación psicoanalítica.

Título: La supervisión psicoanalítica: revisión y una propuesta de sistematización

Endereço para correspondência:

Jacó Zaslavsky

Av. Taquara, 572/301

90460-210 - Porto Alegre - RS

E-mail: jacozas@terra.com.br

Copyright $\odot$ Revista de Psiquiatria do Rio Grande do Sul - SPRS 